\title{
A REVIEW ON MONITORING AND CONTROL PARAMETERS OF GAS PIPELINE BY USING PLC AND SCADA SYSTEM
}

\author{
Rahul S. Joshi, Pritesh P. Patil, Rushikesh N. Dalavi, Abhilash C. Patil, \\ Department of Electrical Engineering Vishwaniketan Institute of \\ Management and Engineering Technology. \\ Mumbai- 410202, India \\ Prof. Sarthak K. Joshi \\ (Assistant Professor) \\ Department of Electrical Engineering Vishwaniketan Institute of \\ Management and Engineering Technology. \\ Mumbai- 410202, India
}

\begin{abstract}
The proposed system monitors and controls the various parameter of gas pipeline system like flow, pressure and temperature using PLC \& SCADA system. In this project, PLC is main controlling device through which whole system is controlled and is visualize through SCADA system. PLC accumulates all information from pressure transducer, flow sensor and temperature sensor. Then finally all this data is assembled and represented in the SCADA system in different layout. SCADA is a most powerful software for monitoring equipment and processing data in real time. It is powerful system of software and hardware deliberated to aid industries in their daily operations.

Also, leakage in pipeline network is one of the foremost causes of countless losses in gas pipeline network. Due to enormous rate of failure of pipeline, it results into human influences, environmental disasters and economic loss.

To overcome such hazard and maintain reliable, safe, and un-interrupting pipeline infrastructure, considerable research efforts have been devoted to employing leakage detection in pipeline using different methodologies.

In this project we are reviewing gas pipeline for PNG (Piped Natural Gas).
\end{abstract}

Keywords- Gas Automation, leakage detection, PNG, PLC \& SCADA system, PID controller.

\section{INTRODUCTION}

All over the world, natural gas is one of the most important source of energy. Even so, gas consumption areas are generally far away from gas storage station and production areas. Due to this, it is very challenging to transport and distribute the gas from storage station to different consumer areas. Also it is very important to continuously monitor and control the parameters of gas pipeline such as temperature, pressure, flow, compressor status, etc. To thoroughly and securely control the gas pipeline, PLC and SCADA system is used.

The PLC and SCADA automatic control system in gas pipeline is used to monitor the parameters of gas pipeline transportation by using all kinds of automatic monitoring \& controlling instruments equipment and instruments. It is used to manage and adjust field equipment. The main aim behind this is to provide the gas to the user in the most economical and the fastest way under the safe condition. In addition to this, the automation system can also decrease the quantity of labor, improve the level of the environment and save the cost. PNG is known as Piped Natural Gas which has huge demand in current scenario. PNG is used for domestic purposes such as cooking and water heating etc. It is also broadly used by commercial as well as industrial sectors like Hotels, Hospitals, Nursing Homes, Flight kitchens, Restaurants, places of Worship etc.

PNG fulfils most of the requirements for fuel across all sections, being efficient, non-polluting and comparatively economical.

\section{LITERATURE SURVEY}

The literature survey is conducted on different monitoring and controlling systems used in gas pipeline automation as well as different methods of leak detection. The average economic loss due to occurrences of pipeline leakages is massive. In USA, due to accidents in pipeline, there is massive property damage which costed nearly $\$ 7$ billion, killed more than 500 people and people who are injured are more than thousands. Similarly, another incident of pipeline failure happened on $6^{\text {th }}$ Sept. 2010 in California, USA where 8 people 
were killed and more than 5o people were injured. The causes of damages in pipeline are not constant, they fluctuates due to different conditions. Fig. 1 shows a pie chart that demonstrates information of the main causes of pipeline failure that include human negligence, defects during installation process, pipeline corrosion, and flaws occurring during the external factors and manufacturing process.

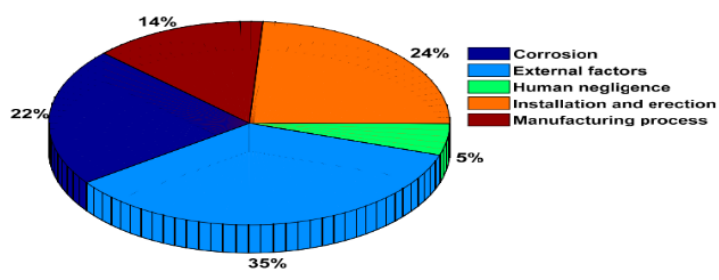

Fig.1 Pie chart showing statistics of the sources of pipeline failure

According to this data, occurrences of pipeline leakages are not that easy to permanently avoid as the sources of failures are different. Though, to reduce the effects of oil and gas leakage on society it is necessary to timely monitor the pipelines for detection of leakage. Hence, it is possible to reduce the injuries, loss rate and other serious social and environmental consequences due to the failure of pipeline.

PNG Properties:

\begin{tabular}{|c|c|}
\hline Physical state & Gas \\
\hline Colour & Colourless \\
\hline Odour & $\begin{array}{l}\text { Odourless (Ethyl Mercaptan is } \\
\text { added as odorant for easy detection } \\
\text { through smell.) }\end{array}$ \\
\hline Boiling point & $161.5^{\circ} \mathrm{C}$ \\
\hline Melting point & $182^{\circ} \mathrm{C}$ \\
\hline Vapour density & 0.6 to 0.7 (w.r.t air) \\
\hline Flammability ratio & 5 to $15 \%$ by volume in air \\
\hline Auto ignition temp. & $540^{\circ} \mathrm{C}$ \\
\hline
\end{tabular}

\section{Growth of PNG:}

Considering safety factors and benefits of PNG, now a days PNG has huge demand and is growing all over the world including India. Economically PNG is more cost saving than other conventional fuels. Also PNG is much safer than other fuels because it is lighter than air and avoids spontaneous flammability. In Mumbai and nearby suburban PNG installation is done and also in some regions the project is ongoing which will be completed within 2 to 3 years. Following table shows growth of PNG in Mumbai region.

\begin{tabular}{|l|l|l|}
\hline Area covered & $\begin{array}{l}\text { Gasification } \\
\text { schedule }\end{array}$ & $\begin{array}{l}\text { Receipt of new } \\
\text { application }\end{array}$ \\
\hline Mumbai & Gasified & Ongoing* \\
\hline Mira - Bhayandar & Gasified & Ongoing* \\
\hline
\end{tabular}

\begin{tabular}{|l|l|l|}
\hline Thane & Gasified & Ongoing* \\
\hline New Mumbai & Gasified & Ongoing* \\
\hline Uran & Gasified & Ongoing* \\
\hline Panvel & $2018-19$ & $2019-20$ \\
\hline Karjat & $2019-20$ & $2019-20$ \\
\hline Khalapur & $2019-20$ & $2020-21$ \\
\hline Pen & $2018-19$ & $2018-19$ \\
\hline Alibaug & $2020-21$ & $2022-23$ \\
\hline Roha & $2020-21$ & $2021-22$ \\
\hline Mangaon & $2020-21$ & $2022-23$ \\
\hline Mahad & $2020-21$ & $2022-23$ \\
\hline
\end{tabular}

Table no. 2.

\section{PROPOSED METHODOLOGY}

\section{Problem Statement: -}

Monitoring and control parameters of gas pipeline using PLC and SCADA.

As stated above, in this project all the parameters of gas pipeline from input i.e. gas storage tank to output i.e. gas filling station are monitor and control by using Programmable Logic Controller (PLC), also these parameters can be remotely control through SCADA screen.

The process flow of the mechanism is carried out in the following way:-

Firstly input parameters of gas pipeline will be measured i.e. parameters of gas storage tank such as pressure and temperature. This pressure and temperature of gas will be maintained constant throughout the gas pipeline using PID controllers. If pressure and temperature of gas are according to desired limits then control valve will open and gas will transfer through pipeline with the help of compressors.

Secondly gas pressure will be checked with the help of pressure transducer to ensure whether the gas pressure is maintain or not. Once the gas pressure without drop is detected then it will allow to pass to the consumer. If any pressure drop will detected then control valve remains close and gas will not be allowed to pass to the consumer.

Through this journey from gas storage tank to the consumer all the parameters will be measured such as temperature, pressure, flow, gas detection, etc. 


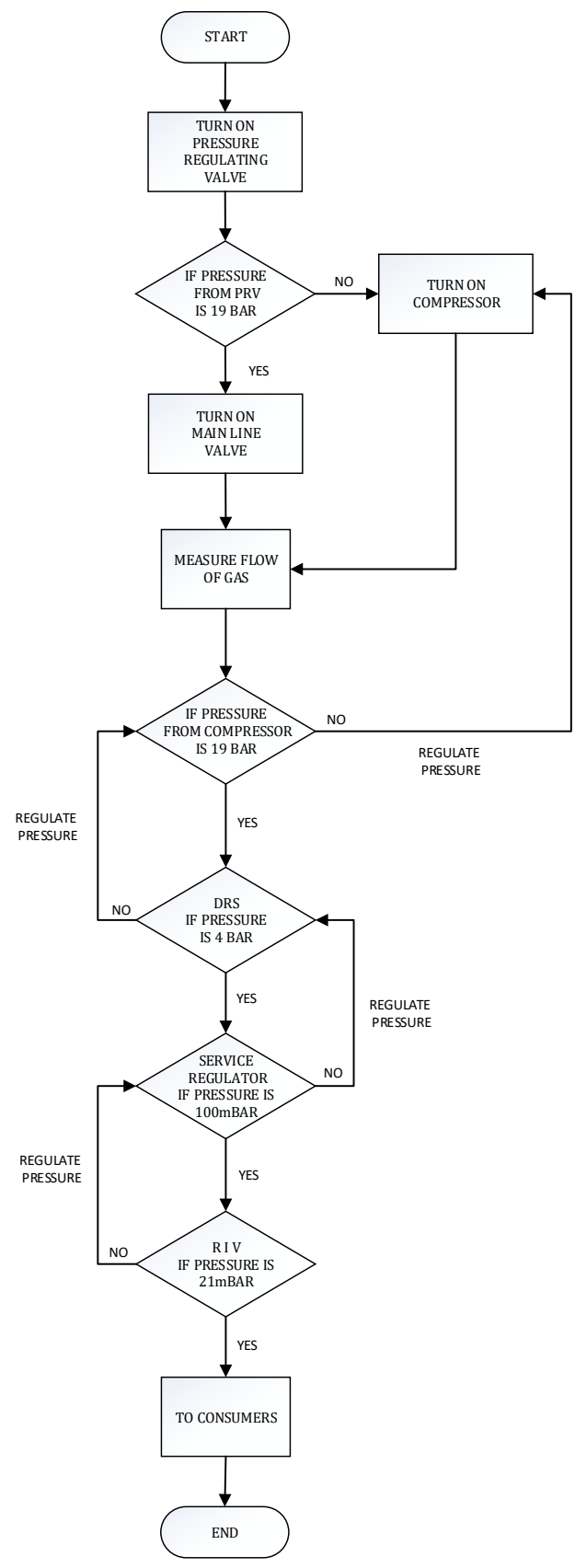

Fig.2 Process flow diagram of system

IV. SOFTWARE REQUIRMENT

- $\quad$ PLC Software: RS LOGIX 500

- Communication software: RS LINX CLASSIC

- SCADA Software: FACTORY TALKVIEW

\section{HARDWARE REQUIRMENT}

- $\quad$ PLC used: ALLEN BRADLY 1400 (series A)
- Solenoid valves, compressor, temperature sensor, flow sensor, pressure transducer, push buttons, etc.

\section{EXPECTED OUTCOMES}

- All sensors should work properly as per set values.

- Temperature of gas storage tanks should be maintained constant.

- Pressure of gas which is to be pass through pipeline should be as per set values.

- $\quad$ Solenoid valves should be operate percentage wise as instructed by PID controllers.

- If any leakage occurs in pipeline then alarm should be $\mathrm{ON}$ and respective line should be close immediately without affecting other pipelines.

- Compressor should adjust the pressure of gas according to instructions from PID controller.

- $\quad$ SCADA screen should operate properly.

\section{ADVANTAGES}

- Man power will be reduced.

- Operation will be automatically controlled.

- Low operating cost.

- Minimize the leakage in pipeline which will save gas.

\section{DISADVANTAGES}

- High initial cost

- Skilled person is required to handle the operation

\section{CONCLUSION}

This project work has deal with the concept of providing an improved monitoring and controlling using the PLC and SCADA system. It will improve in locating the leakage and response will be quick. If there is leakage it will automatically shut off the process for particular area or whole system and also control by manual. The buzzer will alarm if there is any drop in pressure.

\section{REFERENCE}

[1] P. R. P. M. R. S. K. Gosavi, “A Review on Industrial Energy Monitoring System Using PLC and SCADA," Int. Res. J. Eng. Technol., vol. 3, no. 5, pp. 1699-1701, 2016.

[2] M. A. Adegboye, W. K. Fung, and A. Karnik, "Recent advances in pipeline monitoring and oil leakage detection technologies: Principles and approaches," Sensors (Switzerland), vol. 19, no. 11. MDPI AG, 01-Jun-2019, doi: 10.3390/s19112548. 
[3] "Overview." [Online]. Available: https://www.mahanagargas.com/business/domesticpng-overview.aspx. [Accessed: 05-Mar-2020].

[4] "PNG Network." [Online]. Available: https://www.mahanagargas.com/business/pngnetwork.aspx. [Accessed: 06-Mar-2020].

[5] S.Ranjith, D.Srinath, R.Vasantha raja, G.Vignesh, \& R.Rajarajan , Chennai ,(2016, APRIL 3). "Automatic leakage detection \& control of gas pipeline using PLC," International Journal of Emerging Technology in Computer Science \& Electronics (IJETCSE), Volume 21,1-5.

[6] Savitha T.C. (2019, June 2). "PLC and SCADA based irrigation system to monitor the moisture content of agriculture fields," International Journal of Engineering Applied Sciences and Technology, Volume 4, 1-5.

[7] Pimpalkar, P. M., Gattewar, D., Bhoyar, C., Aglawe, P., \& Khobragade, P. (2020, February 10). "IOT based home automation using ATMEGA 328 Microcontroller," International Journal of Engineering Applied Sciences and Technology, Volume 4, 1-5.

[8] Chen-xi WANG, Ming-zhe LIU, Ai-dong XU, \& Jilong ZHANG. (2017). The Application of PLC Control System in Oil and Gas Pipeline Transportation," International Conference on Mechanical Control and Automation (ICMCA 2017), $1-5$.

[9] Ma Rongsuo. "The application of SCADA system in oil and gas pipeline. Digital technology and Applications,"

[10] NaturalGas.org, 2004a, "The Natural Gas Industry and the Environment." Available at http://www.naturalgas.org/environment/ng_industry_ environment.asp. Accessed February 7, 2007.

[11] BANDA .M. K., HERTY . M., \& KLAR ,A. (2010). "Gas flow in pipeline networks,". aims' journals, $x$, 1-17.

[12] Sabu, H. M., B, A. v., Sullerey, A., \& A, B. V. (2015). "Online Monitoring of PLC Based Pressure Control System,". International Journal of Research and Innovations in Science \& Technology, 2(2), 1-4.

[13] S, R., S, K., D, S., \& R, K. (2016, Jan). "Pipeline Monitoring Using Vibroacoustic Sensing - A Review,". International Research Journal of Engineering and Technology (IRJET), 03(01), 1-5. 